\section{Psychoactive substances: Position statement on harm reduction}

The recent special session of the United Nations General Assembly on drugs was timely for several reasons. It is clear that the 'war on drugs' has failed - a singular focus on supply reduction does not work. Worldwide, there have been ongoing changes in the legal status of alcohol, tobacco, marijuana and other psychoactive substances or drugs, as states attempt to develop balanced strategies of supply reduction, demand reduction and harm reduction. There is increasing emphasis on the importance of implementing evidence-based policies to address the significant morbidity and mortality associated with the use of alcohol, tobacco, marijuana and other psychoactive substances. ${ }^{[1-4]}$

Psychoactive substances are subject to several international and national conventions and laws that have emphasised the importance of the 'war on drugs' and supply reduction. At the same time, it is increasingly clear that evidence-based, balanced policies are needed, which address the important differences between alcohol, tobacco, marijuana and other psychoactive substances or drugs. ${ }^{[5]}$ The Prevention of and Treatment for Substance Abuse Act 70 of 2008 speaks to the National Drug Master Plan, which emphasises a range of strategies for addressing the excessive use of alcohol, tobacco, marijuana and other psychoactive substances.

Supply reduction refers to policing efforts to curb the manufacture and distribution of alcohol, tobacco, marijuana and other psychoactive substances or drugs. Demand reduction refers to preventive efforts to decrease their demand. Harm reduction refers to policies and interventions to reduce the harmful consequences of alcohol, tobacco, marijuana and other psychoactive substance use. Focusing on harm reduction does not indicate that risky behaviours in general, and the use of psychoactive substances or drugs in particular, are welcomed. This approach is based rather on the scientific evidence on what works to improve public health and reduce social harms when tobacco, alcohol, marijuana and other psychoactive substances are already being used. ${ }^{[6,7]}$

Not all psychoactive substance use is harmful, although alcohol, tobacco, marijuana and other psychoactive substances are associated with a spectrum of potential harms to individuals and to society. ${ }^{[5]}$ Extrapolating from international knowledge, it is clear that in South Africa (SA) alcohol is the most harmful substance in use, in view of its links with physical illness, mental illness, interpersonal violence and crime. Tobacco is also extremely harmful to individuals and costly for society because of its link with lung cancer and other medical conditions. Marijuana has been associated with many harmful effects, as have a range of other substances. Therefore, evidence-based policies and interventions must address the individuals and communities involved, the drugs being consumed and the environment in which this occurs. ${ }^{[8]}$

Fortunately, growing evidence shows that specific policies and interventions can reduce the potential harms associated with the continued use of psychoactive substances. ${ }^{[6,7]}$ For example, there is considerable evidence that brief psychotherapies are useful for treating sufferers from alcohol, tobacco, marijuana and other drug dependence. Primary care clinicians should screen for abuse and provide evidencebased interventions where indicated. ${ }^{\left[{ }^{[]}\right.}$Other efficacious interventions for reducing harm in people with alcohol, tobacco, marijuana, opioid and other drug use include medication-assisted treatment and needle and syringe programmes. ${ }^{[1,11]}$ Providing such interventions requires the work of many stakeholders; skills must be developed, medications and human resources made available, and health systems strengthened.

\section{Recommendations}

- The National Drug Master Plan emphasises the importance of an integrated approach to supply reduction, demand reduction and harm reduction strategies for combating alcohol, tobacco, marijuana and other psychoactive substance use and abuse in SA.
For any substance, the balance between these three strategies and the approach taken should be evidence-based.

- Data from other countries show that alcohol causes the most individual and societal harm. It is therefore essential to put particular efforts into implementing evidence-based policies and interventions for alcohol harm reduction. This should address upstream drivers of alcohol use, as well as prevention and intervention.

- Efforts to reduce harm have been poorly resourced in SA and, given the enormous profits of the liquor industry, there is a need and obligation for its greater involvement in local harm reduction efforts.

- Local school survey data suggest high rates of experimentation with alcohol, tobacco, marijuana and other drugs during early adolescence. Evidence-based interventions, including a strong focus on harm reduction, are needed in this age group, which comprises a large proportion of South Africans.

- There is little evidence that focusing on supply reduction via criminalisation is effective in reducing alcohol, tobacco, marijuana and other substance abuse. There are insufficient data showing that the commercialisation of such entities is safe, particularly when it is not accompanied by rigorous supply, demand and harm reduction strategies.

- Evidence-based approaches that reduce harm from continued and chronic use of alcohol, tobacco, marijuana and other substances (particularly among vulnerable groups such as adolescents and people with mental disorders) deserve greater attention and additional resources. These include psychotherapy and medicationassisted therapy for individuals, and addressing the structural drivers of continued psychoactive substance use.

- Mental, neurological and substance use disorders contribute significantly to SA's burden of disease. There must be more research attention and a greater focus of clinical resources on this area.

\section{Dan J Stein}

Department of Psychiatry and Mental Health, Faculty of Health Sciences, University of Cape Town, South Africa

dan.stein@uct.ac.za

\section{Eva Manyedi}

School of Nursing, Faculty of Agriculture, Science and Technology, North-West University, Mahikeng, South Africa

For the Executive Committee of the Central Drug Authority (Carol du Toit, Dan Stein, David Bayever, Eva Manyedi, Johlene Ntwana, Lethiwe Ndlovu, Mogotsi Kalaemodimo, Moses Gama, Pelmos Mashabela, Peter Ucko)

1. Chisholm D, Doran C, Shibuya K, Rehm J. Comparative cost-effectiveness of policy instruments for reducing the global burden of alcohol, tobacco and illicit drug use. Drug Alcohol Rev 2006;25(6):553565. DOI:10.1080/09595230600944487

2. Mosher JF, Yanagisako KL. Public health, not social warfare: A public health approach to illegal drug policy. J Public Health Policy 1991;12(3):278-323. DOI:10.2307/3342844

Drucker E. Drug prohibition and public health: 25 years of evidence. Public Health Rep 1999;114(1):1429. DOI:10.1093/phr/114.1.14

Babor TF. Linking science to policy: The role of international collaboration and problem-focused integrative reviews. Addiction 2015;110(Suppl 2):40-46. DOI:10.1111/add.12911

5utt DJ, King LA, Phillips LD, Independent Scientific Committee on Drugs. Drug harms in the UK: A multicriteria decision analysis. Lancet 2010;376(9752):1558-1565. DOI:10.1016/S01406736(10)61462-6

6. Anderson P, Chisholm D, Fuhr C. Effectiveness and cost-effectiveness of policies and programmes to reduce the harm caused by alcohol. Lancet 2009;373(9682):2234-2246. DOI:10.1016/S0140-6736(09)60744-3

. Jones L, Hughes K, Atkinson AM, Bellis MA. Reducing harm in drinking environments: A Jones L, Hughes K, Atkinson AM, Bellis MA. Reducing harm in drinking environments: A
systematic review of effective approaches. Health Place 2011;17(2):508-518. DOI:10.1016/j. systematic review of

healthplace. 2010.12 .006

Van Beek I. Harm reduction - an ethical imperative. Addiction 2009;104(3):342-343, discussion 345 346. DOI:10.1111/j.1360-0443.2008.02418.x

9. Babor TF, McRee BG, Kassebaum PA, et al. Screening, Brief Intervention, and Referral to Treatment (SBIRT): Toward a public health approach to the management of substance abuse. Subst Abuse 2007;28(3):7-30. DOI:10.1300/j465v28n03_03

10. Aspinall EJ, Nambiar D, Goldberg DJ, et al. Are needle and syringe programmes associated with a reduction in HIV transmission among people who inject drugs: A systematic review and metaanalysis. Int J Epidemiol 2014;43(1):235-248. DOI:10.1093/ije/dyt243

11. Timko C, Schultz NR, Cucciare MA, et al. Retention in medication-assisted treatment for opiate dependence: A systematic review. J Addict Dis 2016;35(1):22-35. DOI:10.1080/10550887.2016.1100960

S Afr Med J 2016;106(9):836. DOI:10.7196/SAMJ.2016.v106i9.11223 